\title{
An Intraventricular Schwannoma with Associated Hydrocephalus and Ventricular Entrapment: A Case Report
}

\author{
Sheilah M. Curran-Melendez ${ }^{1}$ Melanie Fukui ${ }^{1}$ William Bivin ${ }^{2}$ David Oliver-Smith ${ }^{3}$ \\ ${ }^{1}$ Department of Radiology, Allegheny Health Network, \\ Pittsburgh, Pennsylvania, United States \\ 2 Department of Pathology, Allegheny Health Network, \\ Pittsburgh, Pennsylvania, United States \\ ${ }^{3}$ Department of Neurosurgery, Allegheny Health Network, \\ Address for correspondence Sheilah M. Curran-Melendez, MD, \\ Department of Radiology, Allegheny Health Network, 320 E \\ North Avenue, Pittsburgh, PA 15212, United States \\ (e-mail: sheilah.curran@gmail.com).
} Pittsburgh, Pennsylvania, United States

J Neurol Surg Rep 2015;76:e32-e36.

\begin{abstract}
Intraventricular schwannomas are rare primary brain tumors, with fewer than 25 cases reported in the literature. Here, we present the case of a 20-year-old male patient with a 2 year history of blurry vision and dysesthesia involving his right occiput and upper neck.

Keywords

- ventricles

- brain

- schwannoma

- hydrocephalus Imaging demonstrated a homogeneously enhancing mass located within the atrium of the right lateral ventricle with associated right lateral ventricular entrapment. Pathology confirmed the tumor to be an intraventricular schwannoma. Imaging findings, presentation, complications, and treatment options for intraventricular schwannomas are described.
\end{abstract}

\section{Case Presentation}

A 20-year-old male patient without significant medical history presented to an urgent care facility for the evaluation of intermittent blurry vision which had been present for approximately 2 years. The patient additionally complained of dysesthesia: a burning sensation, located at the upper neck and right occiput, intermittent in occurrence and lasting only a few seconds, but increasing in intensity and severity over the previous 2 months.

Physical examination found the patient to be awake, alert, and oriented. Pupils were equal, round, and reactive to light and accommodation. A fundoscopic examination was not performed. Cranial nerves II-XII were intact; specifically, extraocular motion was intact. Reflexes and range of motion were normal, and the strength of the bilateral upper and lower extremities was $5 / 5$. Sensation, proprioception, muscle tone, and gait were intact.

Initial radiologic evaluation included an unenhanced computed tomography (CT) scan of the head which showed a right temporal horn intraventricular mass, with surrounding white matter edema and dilation of the right lateral ventricle. Subsequent evaluation with an enhanced magnetic resonance imaging (MRI) of the head included T2, $\mathrm{T} 2$, fluid-attenuated inversion recovery, diffusion-weighted, and $\mathrm{T} 1$-unenhanced images in the axial plane. Unenhanced T1-weighted images were acquired in the sagittal plane, as well as enhanced T1-weighted images in the axial, coronal, and sagittal planes. In aggregate, these images showed a $2.1 \times 1.9 \times 2.6 \mathrm{~cm}$ (transverse $\times$ anterior-posterior $\times$ superior-inferior) mass, located within the atrium of the right lateral ventricle. The mass demonstrated mild $\mathrm{T} 1$ hypointensity ( - Fig. 1A) with areas of heterogeneous T2 hyperintensity ( $\mathbf{- F i g . 2 A}$ ).

Foci of susceptibility artifact within the mass (-Fig. 3) were suggestive of calcification or hemosiderin deposition from previous hemorrhage. Postcontrast images displayed homogeneous enhancement (-Fig. 1B, C). Within the white matter of the surrounding right parietal and inferior right temporal lobes, there was a large amount of edema (-Fig. 2A). Asymmetric enlargement of the right lateral
License terms

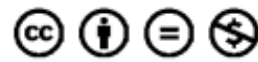

(c) 2015 Georg Thieme Verlag KG Stuttgart · New York 10.1055/s-0034-1395493. ISSN 2193-6366. accepted after revision

August 6, 2014

published online

January 16, 2015 

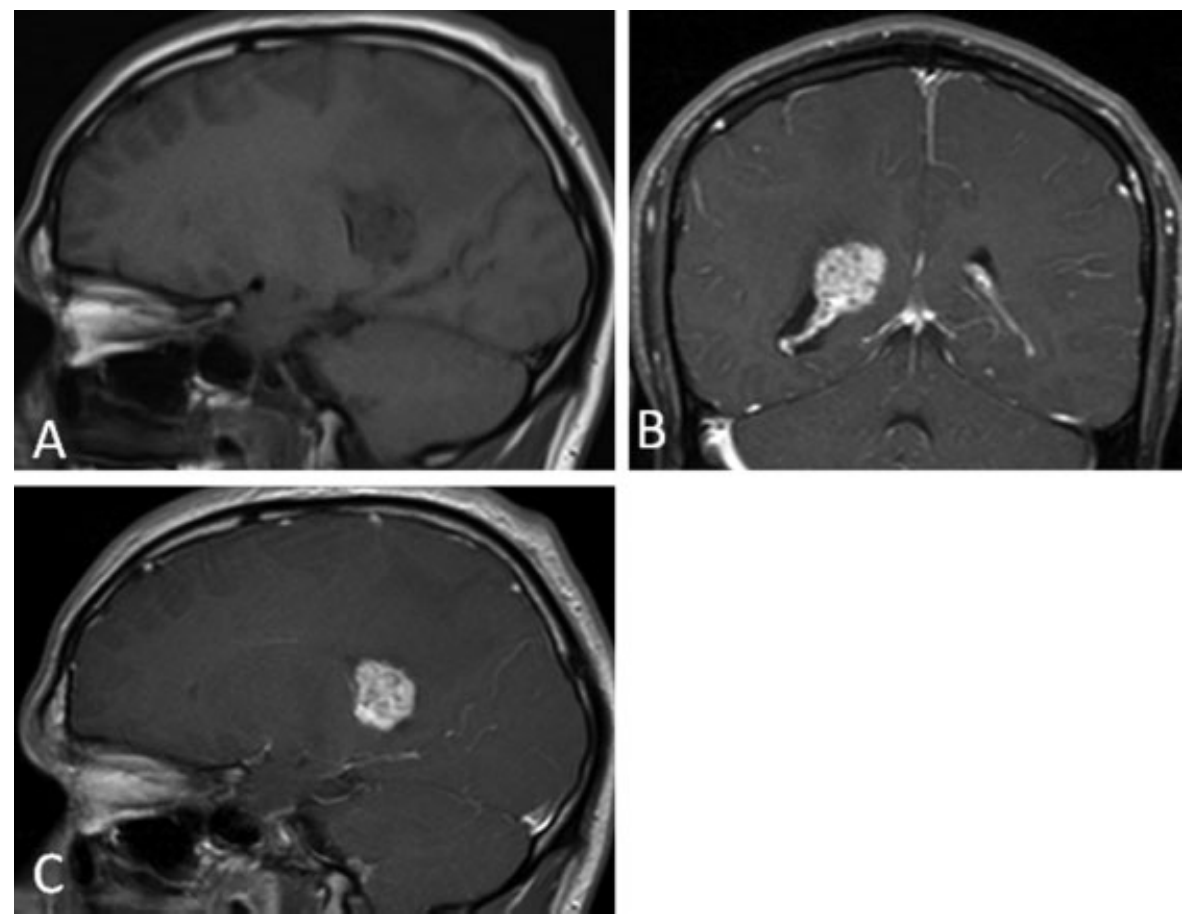

Fig. 1. T1-weighted magnetic resonance imaging of the brain before $(A)$ and after $(B, C)$ the administration of gadolinium-based contrast demonstrate a midly $\mathrm{T} 1$ hypointense, avidly enhancing mass within the right lateral ventricle.
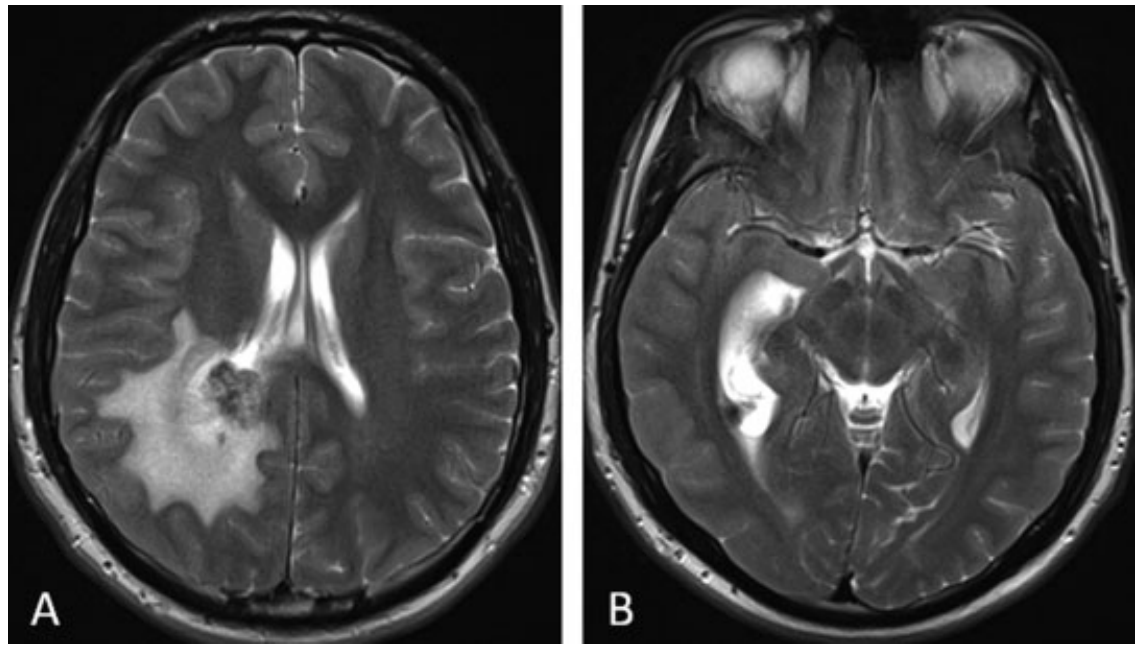

Fig. 2 . T2-weighted magnetic resonance imaging of the brain demonstrate a heterogeneously hyperintense mass within the right lateral ventricle. Enlargement of the posterior horn of the right lateral ventricle with surrounding white matter edema is consistent with ventricular entrapment.

ventricle (-Fig. 2B), particularly at the level of the right temporal horn, was suggestive of ventricular entrapment. The third and fourth ventricles were normal in size. The primary radiographic consideration was a meningioma, although ependymoma and choroid plexus papilloma were in the differential.

The patient underwent surgical resection of the tumor through a right parietal craniotomy, with a transparietal approach, and intraventricular shunt placement for treatment of associated ventricular entrapment. Gross examination demonstrated the tumor to be well encapsulated and adherent to the medial aspect of the right lateral ventricle wall. Areas of moderate calcification were noted.

Pathologic evaluation demonstrated densely packed fascicles of spindle cells with elongated nuclei representing Antoni A tissue (-Fig. 4). These were mixed with areas of loosely packed, hypocellular foci of spindle cells with small, round nuclei within myxoid matrix. This was consistent with Antoni B tissue (-Fig. 5).

Positive S-100 staining confirmed the Schwann cell origin of the tumor while the negative epithelial membrane antigen confirmed that the tumor was not meningeal in origin. Glial 


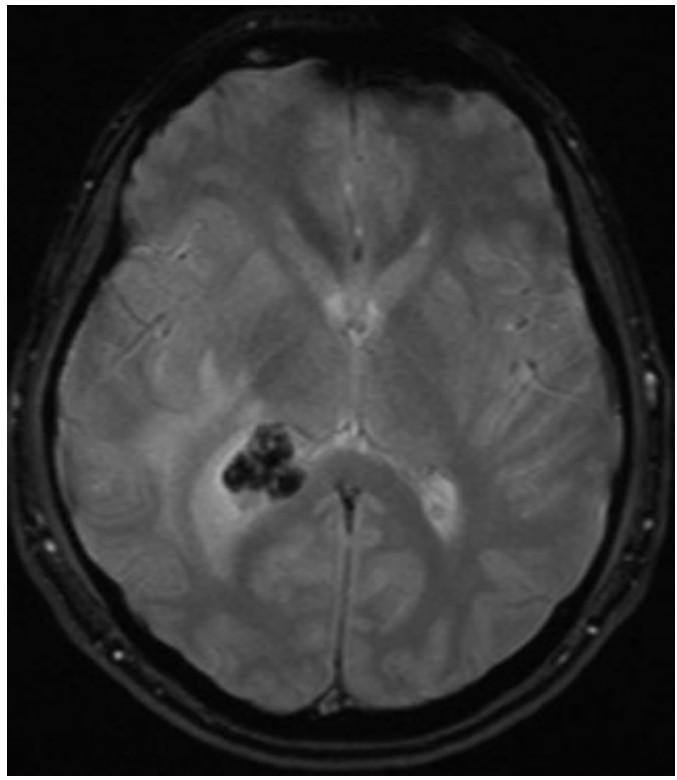

Fig. 3 T2*-weighted magnetic resonance imaging of the brain demonstrates susceptibility artifact within the mass, representing foci of calcification.

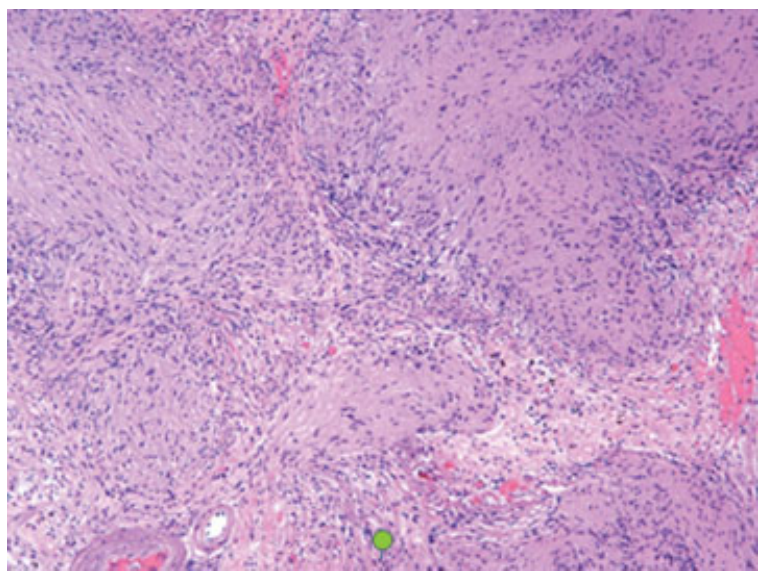

Fig. 4 Hematoxylin-eosin staining viewed at $\times 200$ magnification demonstrates densely packed fascicles of spindle cells with elongated nuclei (Antoni A).

fibrillary acidic protein was also positive, a marker which may be variably positive in schwannomas, but which is often positive in intracranial schwannomas. MIB-1 stain demonstrated low nuclear positivity, consistent with a benign process.

The patient is currently 9 months out from surgical resection of the tumor without radiographic evidence of residual or recurrent tumor.

\section{Discussion}

Schwannomas account for $8 \%$ of all primary brain tumors. ${ }^{1}$ Most schwannomas are associated with cranial nerves, most commonly cranial nerves VIII, V, and VII, and 80 to $90 \%$ are

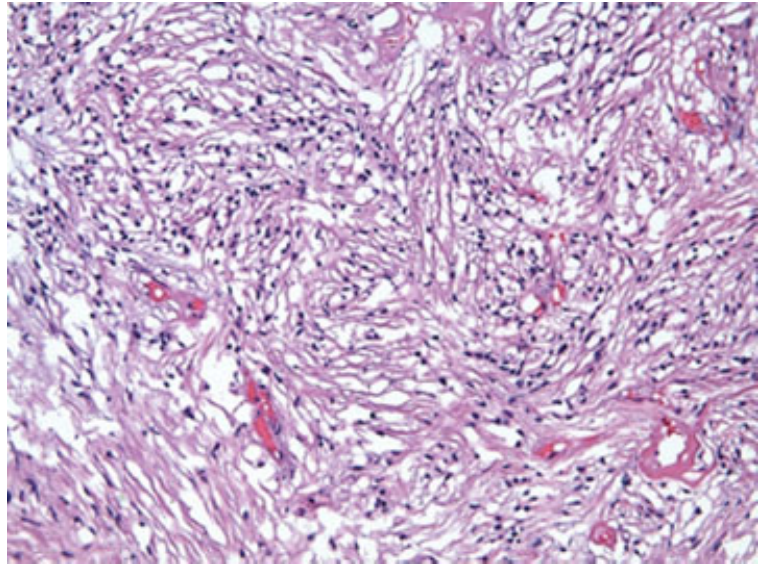

Fig. 5 Hematoxylin-eosin staining viewed at $\times 200$ magnification demonstrates a loosely packed, hypocellular focus of spindle cells with small, round nuclei in a myxoid matrix (Antoni B).

located in the region of the cerebellopontine angle. ${ }^{2}$ They have also been associated with spinal nerve roots and have been found in the retroperitoneum and mediastinum. Rarely, schwannomas have been noted to arise from intracranial locations, a subset of which have been described as intraventricular in location.

The earliest reported case of an intraventricular schwannoma was described by Marchand et al in $1957 .{ }^{3}$ Since then 23 cases have been reported in the literature (-Table $\mathbf{1}$ ).

Among these cases there is almost a 2:1 male-to-female predominance. The median age of presentation is 31 years, with a reported age range of 7 to 78 years. Overall, 21 of the reported cases were benign in etiology with only 2 reported cases demonstrating malignant features. ${ }^{3,4}$ These lesions are most often located within the lateral ventricles (70\%) but have also been found in the fourth (26\%) and third (4\%) ventricles. The most common complication associated with intraventricular schwannoma is the presence of hydrocephalus.

The clinical presentation of an intraventricular schwannoma often varies but most commonly involves headache, nausea, and vomiting. Brachial-crural hemiparesis, seizures, vertigo, and visual symptoms such as homonymous hemanopsia and transient scintillating scotomas have also been reported. These lesions may also be asymptomatic and only detected incidentally, through papilledema or retinal hemorrhage seen on an ophthalmic screening examination.

Currently, the etiology of intraventricular schwannomas is unknown, although three theories are often mentioned in the literature. The most popular theory postulates that intraventricular schwannomas are the result of hyperplastic transformation of Schwann cells associated with peripheral or autonomic nerve fibers located within the choroid plexus. ${ }^{5}$ This theory is supported by the identification of peripheral nerve fibers within the choroid plexus of the fourth ventricle. ${ }^{6}$ Another theory is neoplastic transformation of ectopic neural crest cells located within the ventricles due to disorganized embryogenesis, ${ }^{7,8}$ a theory 
Table 1 Reported cases of intraventricular schwannoma

\begin{tabular}{|c|c|c|c|c|c|}
\hline Age (y) & Gender & Location & Benign/malignant & Year & Citation \\
\hline 44 & Male & Lateral (occipital) & Benign & 1990 & Ost et $\mathrm{al}^{5}$ \\
\hline 21 & Male & Lateral (temporal) & Benign & 1975 & Van Rensburg $^{12}$ \\
\hline 63 & Female & Lateral & Benign & 1975 & Ghatak $^{13}$ \\
\hline 8 & Male & Lateral & Benign & 1988 & Pimentel et al $^{14}$ \\
\hline 40 & Male & Lateral (temporal) & Malignant & 1995 & Jung et $\mathrm{al}^{4}$ \\
\hline 15 & Male & Lateral & Benign & 1965 & David et al ${ }^{15}$ \\
\hline 7 & Male & Fourth & Benign & 1990 & Redekop et al ${ }^{16}$ \\
\hline 16 & Male & Lateral (trigone) & Benign & 2004 & Dow et $\mathrm{al}^{7}$ \\
\hline 15 & Male & Lateral (occipital) & Benign & 2008 & Benedict et al ${ }^{11}$ \\
\hline 21 & Male & Lateral & Benign & 2003 & Erdogan et al ${ }^{17}$ \\
\hline 21 & Female & Third & Benign & 2006 & Messing-Jünger et al ${ }^{18}$ \\
\hline 71 & Female & Fourth & Benign & 2009 & Oertel et al ${ }^{10}$ \\
\hline 36 & Female & Fourth & Benign & 2002 & Estrada $^{19}$ \\
\hline 16 & Male & Lateral & Benign & 2007 & Lévêque et $\mathrm{al}^{20}$ \\
\hline 13 & Female & Lateral & Benign & 2001 & 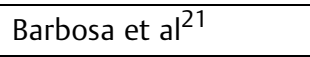 \\
\hline 43 & Male & Fourth & Malignant & 1957 & Marchand et $\mathrm{al}^{3}$ \\
\hline 21 & Male & Lateral & Benign & 2013 & Luo et $\mathrm{al}^{2}$ \\
\hline 61 & Male & Fourth & Benign & 1993 & Weiner et $\mathrm{al}^{22}$ \\
\hline 78 & Female & Fourth & Benign & 1993 & Weiner et $\mathrm{al}^{22}$ \\
\hline 16 & Male & Lateral (occipital) & Benign & 2013 & Jaimovich et $\mathrm{al}^{9}$ \\
\hline 16 & Male & Lateral & Benign & 1993 & Casadei $^{23}$ \\
\hline 49 & Female & Lateral & Benign & 1993 & Casadei $^{23}$ \\
\hline 21 & Female & Lateral (occipital) & Benign & 2009 & Vasconcellos et al $^{24}$ \\
\hline
\end{tabular}

that is supported by reported instances of schwannoma attachment to the choroid plexus. The final theory involves neoplastic transformation of pluripotent mesenchymal cells into Schwann cells after tissue injury. ${ }^{9}$ No association between intraventricular schwannomas and genetic syndromes has been identified.

The ubiquitous availability of CT means it is often the modality used for the initial evaluation of intraventricular schwannoma. Intraventricular schwannomas have been described as both hypodense and hyperdense, with possible cystic components. Calcifications are often present. On MRI, intracranial schwannomas are predominantly solid with cystic components. Solid components are most often homogeneously T1 hypointense with heterogeneous T2 hyperintensity. The cystic components mostly follow simple fluid characteristics (T1 hypointensity, T2 hyperintensity). The enhancement pattern has been described as heterogeneous both on CT and MR studies, and attachment to the choroid plexus and ventricle wall may be visualized. Associated periventricular edema may be visualized on both CT and MRI. Due to the rarity of these lesions, the differential diagnosis is mostly based on imaging findings and lesion location. The imaging differential diagnosis includes cystic astrocytomas, cystic meningiomas, ependymoma, choroid plexus papilloma, choroid plexus carcinoma, hemangioblastoma, and metastatic lesions.

Primary treatment is complete surgical resection. For tumors located within the lateral ventricles, a transcortical approach with osteoplastic craniotomy is favored. ${ }^{10}$ When the tumor is located in the third or fourth ventricles, a midline suboccipital approach is generally performed. ${ }^{10}$ Although complete surgical resection is always the preferred treatment, occasionally tumors may involve intracranial vessels or invade cerebral parenchyma, and complete resection may not be possible. In the single reported case where complete resection was not possible and pathology demonstrated malignancy, subsequent treatment with whole brain radiation was also performed (Jung et al). In cases of benign intraventricular schwannomas where complete resection is not possible, close radiologic follow-up is often pursued. ${ }^{11}$

Only two cases of malignant intraventricular schwannomas have been reported (Jung et al and Marchand et al). In the case of Jung et al, the schwannoma was incompletely resected due to tumor invasion and treated with subsequent whole brain radiation. Tumor recurrence with metastatic disease to the left cerebellopontine angle and cerebellar surface was diagnosed 4 months after the initial surgery. 


\section{Conclusions}

Here, we present a case of right atrial intraventricular schwannoma causing right lateral ventricle entrapment. Although a rare cause of primary central nervous system neoplasm, with fewer than 25 cases reported in the literature, clinicians should keep intraventricular schwannoma in mind when evaluating enhancing intraventricular masses. These lesions are most often benign and may be fully cured with surgical resection.

\section{References}

1 Russell DS, Rubinstein LJ. Pathology of tumors of the nervous system. 4th ed. London: Edwards Arnold; 1977:372-379

2 Luo W, Ren X, Chen S, Liu H, Sui D, Lin S. Intracranial intraparenchymal and intraventricular schwannomas: report of 18 cases. Clin Neurol Neurosurg 2013;115(7):1052-1057

3 Marchand L, Koechlin P, Racine Y. Malignant neurinoma of the fourth ventricle with intrabulbar propagation in a schizophrenic; death during electroshock [in French]. Ann Med Psychol (Paris) 1957;115(1):108-113

4 Jung JM, Shin HJ, Chi JG, Park IS, Kim ES, Han JW. Malignant intraventricular schwannoma. Case report. J Neurosurg 1995; 82(1):121-124

5 Ost AH, Meyer R. Cystic intraventricular schwannoma: a case report. AJNR Am J Neuroradiol 1990;11(6):1262-1264

6 Benedickt M. Ueber die Innervation des Plexus choroideus. Virchows Arch Pathol Anat 1874;59:395-400

7 Dow GR, Hussein A, Robertson IJ. Supratentorial intraventricular schwannoma. Br J Neurosurg 2004;18(5):561-562

8 Ramamurthi B, Anguli VC, Iyer CGS. A case of intramedullary neurinoma. J Neurol Neurosurg Psychiatry 1958;21(2):92-94

9 Jaimovich R, Jaimovich SG, Arakaki N, Sevlever G. Supratentorial intraventricular solitary schwannoma. Case report and literature review. Childs Nerv Syst 2013;29(3):499-504

10 Oertel MF, Nolte KW, Blaum M, Weis J, Gilsbach JM, Korinth MC. Primary intraventricular schwannomas. Clin Neurol Neurosurg 2009;111(9):768-773
11 Benedict WJ Jr, Brown HG, Sivarajan G, Prabhu VC. Intraventricular schwannoma in a 15-year-old adolescent: a case report. Childs Nerv Syst 2008;24(4):529-532

12 Van Rensburg MJ, Proctor NS, Danziger J, Orelowitz MS. Temporal lobe epilepsy due to an intracerebral Schwannoma: case report. J Neurol Neurosurg Psychiatry 1975;38(7):703-709

13 Ghatak NR, Norwood GW, Davis GH. Intracerebral schwannoma. Surg Neurol 1975;3:45-57

14 Pimentel J, Tavora L, Cristina ML, Antunes JA. Intraventricular schwannoma. Childs Nerv Syst 1988;4(6):373-375

15 David M, Guyot JF, Ballivet J, Sachs M. Schwannoid tumor of the lateral ventricle [in French]. Neurochirurgie 1965;11(6):578-581

16 Redekop G, Elisevich K, Gilbert J. Fourth ventricular schwannoma. Case report. J Neurosurg 1990;73(5):777-781

17 Erdogan E, Ongürü O, Bulakbasi N, Baysefer A, Gezen F, Timurkaynak E. Schwannoma of the lateral ventricle: eight-year follow-up and literature review. Minim Invasive Neurosurg 2003;46(1): 50-53

18 Messing-Jünger AM, Riemenschneider MJ, Reifenberger G. A 21year-old female with a third ventricular tumor. Brain Pathol 2006; 16(1):87-88, 93

19 Estrada MJ, Sánchez Rodríguez G, Farías García R. Calderón Garcidue ñas AL. Schwannoma del cuarto ventrículo. Rev Med Inst Mex Seguro Soc 2002;40(5):405-408

20 Lévêque M, Gilliard C, Godfraind C, Ruchoux MM, Gustin T. Intraventricular schwannoma: a case report [in French]. Neurochirurgie 2007;53(5):383-386

21 Barbosa MD, Rebelo O, Barbosa P, Gonçalves J, Fernandes R. Cystic intraventricular schwannoma: case report and review of the literature. Neurocirugia (Astur) 2001;12(1):56-60

22 Weiner HL, Zagzag D, Babu R, Weinreb HJ, Ransohoff J. Schwannoma of the fourth ventricle presenting with hemifacial spasm. A report of two cases. J Neurooncol 1993;15(1):37-43

23 Casadei GP, Komori T, Scheithauer WB, Miller GN, Parisi JE, Kelly PJ. Intracranial parenchymal schwannoma. A clinicopathological and neuroimaging study of nine cases. J Neurosurg 1993;79(2): 217-222

24 Vasconcellos LP, Santos AR, Veiga JC, Schilemann I, Lancellotti CL. Supratentorial intraventricular schwannoma of the choroid plexus. Arq Neuropsiquiatr 2009;67(4):1100-1102 